\title{
SELF-CARE ACTIVITIES AMONG PATIENTS WITH TYPE 2 DIABETES MELLITUS IN PENAMPANG, SABAH AND ITS ASSOCIATION WITH DEPRESSION, ANXIETY AND STRESS
}

\author{
Mirah Papo ${ }^{1}$, Hizlinda Tohid ${ }^{2}$, Saharuddin Ahmad ${ }^{2}$, Aini Simon Sumeh ${ }^{1}$, Teh Rohaila Jamil ${ }^{2}$ and Zuhra \\ Hamzah $^{2}$ \\ ${ }^{1}$ Klinik Kesihatan Penampang, Ministry of Health Malaysia, Jalan Tambunan, Peti surat 999, 89500, Penampang, Sabah, \\ Malaysia. \\ ${ }^{2}$ Department of Family Medicine, Faculty of Medicine, Universiti Kebangsaan Malaysia, Jalan Yaacob Latif, Bandar Tun \\ Razak, 56000, Cheras, Kuala Lumpur, Malaysia.
}

Corresponding author: Dr Hizlinda Tohid

E-mail: hizlinda2202@gmail.com

\begin{abstract}
Performing self-care activities can be challenging but it is important for favourable outcomes of type 2 diabetes mellitus (T2DM). It may be influenced by psychological problems. Therefore, this study examined the level of self-care activities and the presence of psychological problems among patients with T2DM. The association between these activities and the psychological problems was assessed too. This cross-sectional study was conducted at a public health clinic in Sabah. Data was collected between July and September 2017 using a validated self-administered questionnaire which include the depression, anxiety and stress scale-21 (DASS-21) and the summary of diabetes self-care activities (SDSCA) questionnaire. About $91 \%$ of 331 participants took diabetes medications in $\geq 6$ days per week. They followed a healthful eating plan, inspected feet and exercised 30 minutes a day in 5.0 (IQR 4.0), 4.0 (IQR 7.0) and 1.0 (IQR 4.0) days per week respectively. Among owners of glucometer, the median (IQR) of monitoring blood glucose was 1.0 (1.0) days per week. The participants with depression, anxiety and stress were $4.5 \%, 8.8 \%$ and $5.7 \%$ respectively. Following a healthful eating plan $(p<0.001)$ was found to be significantly associated with anxiety; those with anxiety practised this activity in fewer days than those without anxiety. Generally, self-care activities were poorly practiced by the participants, except for taking diabetes medications. Thus, the patients should be encouraged to improve their selfcare activities. Psychological problems were also found to be uncommon. However, anxiety symptoms should not be ignored as it may negatively affect their adherence to healthy diet.
\end{abstract}

Keyword: self-care activities, depression, anxiety, stress, type 2 diabetes mellitus

\section{INTRODUCTION}

Worldwide, Type 2 Diabetes Mellitus (T2DM) has become more prevalent and its global prevalence among adults has doubled to $8.5 \%$ over more than three decades. ${ }^{1}$ This increasing prevalence of T2DM is also observed in Malaysia whereby the prevalence had raised from $15.2 \%$ to $17.5 \%$ over the last half decade. ${ }^{2,3}$ As a result of this, mortality and morbidity due to T2DM have increased as well and the quality of life of patients with T2DM is significantly affected. ${ }^{1}$

Various strategies have been carried out to improve the outcomes of patients with T2DM. One of these strategies is to advocate the patients to regularly perform self-care activities. These activities are practices done by them to preserve or improve their own health, such as eating healthily, performing regular exercise, testing blood glucose at home, compliantly taking medications and carrying out foot care. ${ }^{1,4,5}$ Previous studies have shown that patients with higher levels of self-care activities had lower HbA1C level, better quality of life and reduced hospitalisations. ${ }^{6-8}$
Level of self-care activities among patients with T2DM has been studied worldwide9-15 and locally in peninsular Malaysia ${ }^{16-19}$. A systematic review by Coyle et al. (2013) concluded that patients with T2DM practiced these activities regularly at various degree. ${ }^{9}$ The most frequently performed self-care activity is taking medications,, $911-15$ whereas eating healthily and performing foot care are practiced moderately ( 3 to 5 days per week). ${ }^{11-15}$ However, exercising regularly and monitoring blood glucose level were diversely performed by patients in different countries, in which either one was the least performed..$^{10-15} \mathrm{It}$ appears that patients from the USA monitored their sugar level more often compared to those from other less developed countries. ${ }^{10-13,15}$ In Malaysia, monitoring blood glucose level was the least practised, whereas other self-care activities were moderately practiced. ${ }^{16-19}$ These studies, however, did not assess the patients' adherence to diabetic medications. ${ }^{16-19}$

There are various factors that could influence the level of self-care activities and presence of psychological problems such as depression, anxiety and stress is one of these factors, ${ }^{20,21}$ which are found to be quite common among 
patients with T2DM. In Malaysia, the prevalence of depression, anxiety and stress among patients with T2DM are 11.5-40.3\%, 30.5-31.4\% and 12.5$50.5 \%$ respectively. ${ }^{22-25}$ Adherence to diet, physical activity and diabetic medications was shown to be adversely affected by psychological problems particularly depression. ${ }^{26-33}$ However, the influence of these psychological problems on diabetic self-care activities among Malaysians has not been well studied.

In Malaysia specifically Sabah, studies that examined self-care activities among patients with T2DM is still lacking. Furthermore, the prevalence of psychological problems among these patients are still unknown. Since Sabah has 32 ethnicities with different cultural and socioeconomic backgrounds which can influence their psychological states and how they practice selfcare activities, it is important to examine the level of their self-care activities and the prevalence of these psychological problems. Therefore, this study aimed to examine diabetic self-care activities, prevalence of depression, anxiety and stress along with assessing the association between these two variables among patients with T2DM attending a public health clinic in Sabah. A sub-analysis to examine the association of these two variables with $\mathrm{HbA} 1 \mathrm{c}$ was also done. We hope the findings of this study could provide information that allows stakeholders to strategise interventions to improve patients' selfcare activities and psychological states, which subsequently could lead to better glycaemic control.

\section{METHODOLOGY}

This cross-sectional study was carried out at a public health clinic in Penampang, Sabah which is one of the largest public health clinics on the west coast of Sabah. It provides primary healthcare service to an urban population within 13000kilometre radius of the clinic. It runs a diabetic clinic every day by a multidisciplinary team and there was about 2500 registered patients with T2DM at the time of the study.

The sample size required to answer the primary objectives (i.e. the level of self-care activities) was 70 participants and this was calculated using a simple mean formula. However, to examine the proportions of patients with depression, anxiety and stress, the sample size required was 277 , calculated using a simple proportion formula for finite population. Both calculations utilised $95 \%$ confidence interval and precision of 0.5. After considering $20 \%$ non-response rate, the total sample size was 332 .

The data was collected over three months between July and September 2017 through convenience sampling. About 803 patients with T2DM who met the inclusion and exclusion criteria were approached but only 331 gave their written consent. The inclusion criteria were those aged 18 years or above and able to read English and/or Bahasa Malaysia. The exclusion criteria included patients who were dependent for their activities of daily living (ADL), physically disabled, pregnant, having underlying psychiatric disorder and required emergency treatment during the clinic visit. All participants completed a selfadministered questionnaire which was written in both English and Bahasa Malaysia. They took up to 30 minutes to complete it with or without assistance from others. The questionnaire assessed the participants' sociodemographic data, duration of T2DM, level of self-care activities and presence of psychological problems. Presence of diabetic complications, co-morbidities and HbA1c were examined by reviewing the participants' case notes. Any illnesses and diabetic complications diagnosed by previous doctors were recorded for analysis.

This study utilised the summary of diabetes selfcare activities (SDSCA), which was developed by Toobert et al (2000) $)^{5}$ and translated into Bahasa Malaysia (BM) by Jalaludin et al. $(2012)^{34}$. The BM version of SDSCA was subsequently validated among adults with T2DM by Bujang et al. (2016). ${ }^{35}$ In this study, bilingual SDSCA was used to examine the participants' compliance in performing five main self-care activities including following a healthful eating plan (2 items), performing exercise for at least 30 -minute in a day (1 item), checking feet (1 item), monitoring blood-glucose level (1 item) and taking the recommended diabetes medications ( 1 item). The original SDSCA was adapted by including the definition of healthful eating plan and photos of food to improve the participants' understanding of the assessed self-care activities (Figure 1). For this study, the healthful eating plan was defined according to the diabetes portion plate: $1 / 2$ plate of vegetables, $1 / 4$ plate of protein and $1 / 4$ plate of carbohydrate. This adaptation was deemed necessary based on feedbacks from eight patients with T2DM who attended the same clinic prior to the actual study. They had difficulties to answer the items that contain 'healthful eating plan' as they did not understand the term. A dietician and two-family medicine specialists assisted in the adaptation of the SDSCA and the comprehensibility of the adapted version was examined among eight patients for face validity. The level of each self-care activities was presented in the number of days within a week; the greater the number of days, the better the practice. For the self-care activity of following a healthful eating plan, the mean number of days for the two items was calculated and presented. For home blood glucose monitoring (HBGM), the level of this practice was differentiated among those who used insulin, took oral hypoglycaemic agents (OHA) only and owned a glucometer. This is because HBGM is especially emphasised for those who use insulin as it helps them to titre their insulin. ${ }^{4}$ Since owning a glucometer could 
influence the practice of monitoring blood glucose level at home, only those who owned a glucometer were included in the bivariate analysis.

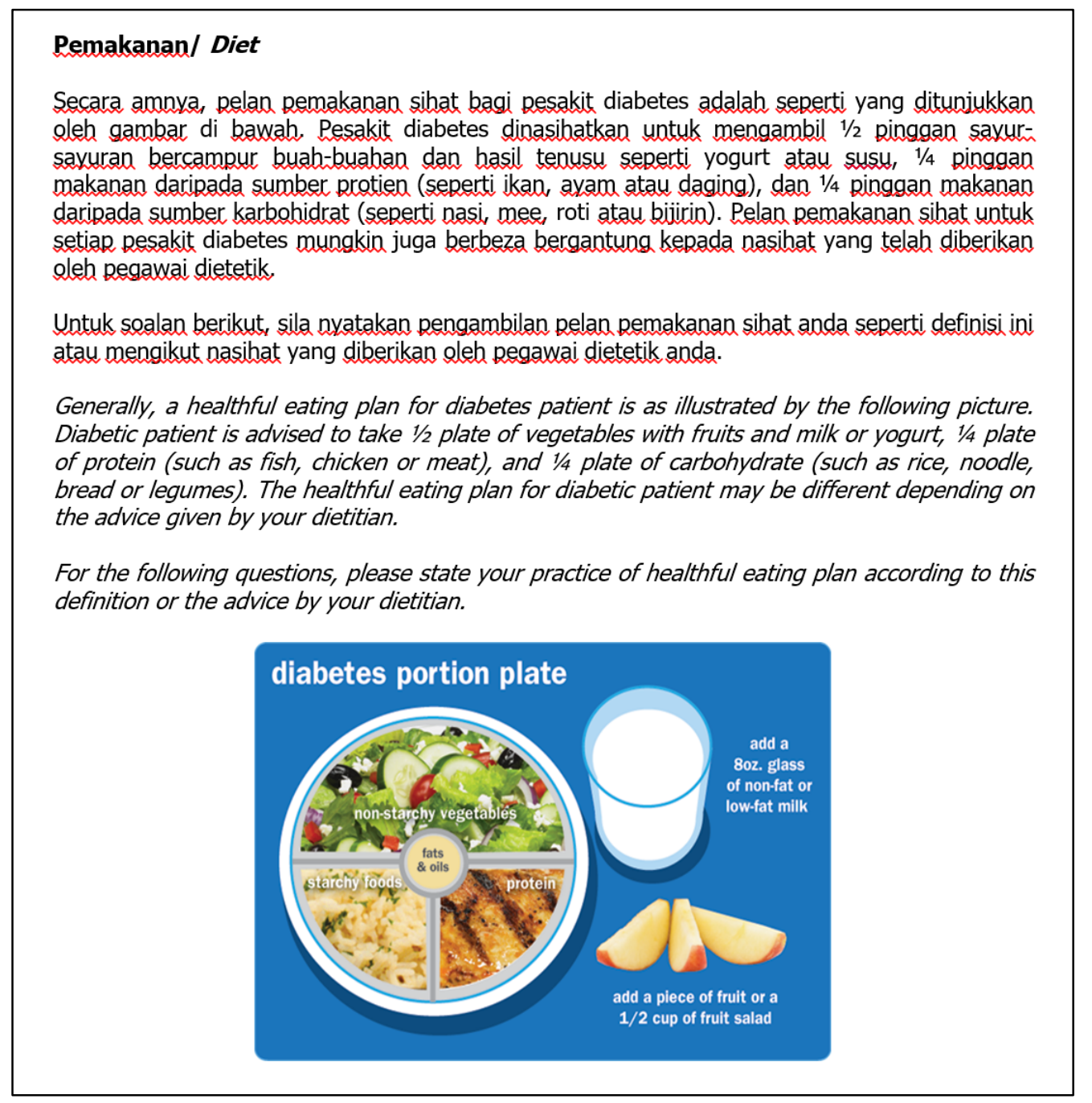

Figure 1: The definition of healthful eating plan included in the adapted SDSCA

To examine the presence of psychological problems, the depression, anxiety and stress scale-21 (DASS-21) was used. There was a total of 21 items that describe conditions related to these psychological states with a 4-Likert scale response of 0 (did not apply to me at all over the last week) to 3 (applied to me very much or most of the time over the past week). The score of seven items in each domain was calculated. The presence of depression, anxiety and stress was determined by using a cut-off scoring level of 9,7 and 14 respectively based on the recommendation by Musa et al. ${ }^{36}$

The ethical approval to carry out this study was obtained from the Research Ethic Committee Universiti Kebangsaan Malaysia (Project code: FF2016-116) and the Medical Research and Ethics Committee, Ministry of Health Malaysia (NMRR ID: 28793). Both DASS-21 and SDSCA are public domains but permission to use the Bahasa Malaysia version of DASS 21 and SDSCA were obtained from the authors of these versions. Participants who were found to have psychological problems through this study were referred to a mental health unit at the same public health clinic for further assessment and management.

Data was analysed using IBM SPSS Statistics version 23. All categorical data was described as frequency (n) and percentage (\%). Since all the continuous data were not normally distributed, it was described as median and interquartile range (IQR). For bivariate analysis, a non-parametric Mann-Whitney test was used to examine the association of the psychological problems (categorical data) with the practice of each selfcare activity and $\mathrm{HbA1C}$. The associations between self-care activities and HbA1c was examined by using Spearman's Rho correlation as both continuous data were non-normally distributed. A p-value less than 0.05 indicates a significant association between the analysed variables.

\section{RESULT}

\section{Characteristics of the participants}

The median (IQR) for age of the participants was $60.0(14.0)$ years whereby $48.0 \%$ of them aged more than 60 years (Table 1 ). There were almost 
similar proportions of females $(52.6 \%)$ and males (47.4\%). Bumiputera (i.e. natives of Sabah) were the majority $(85.8 \%)$. Almost all were married (93.7\%) and lived with others (97.3\%). More than a half $(59.2 \%)$ was unemployed and the median (IQR) for monthly income was RM 1300.00
(2200.00). Majority of them (81.3\%) earned RM 3000.00 or less in a month and this cut-off level was based on the median monthly household income of the bottom $40 \%$ of the Malaysian population (B40 group). ${ }^{37}$

Table 1: Characteristics of the respondents $(\mathrm{N}=331)$

\begin{tabular}{|c|c|c|}
\hline Characteristics & Median (IQR) & n (\%) \\
\hline Age (years) & $60.0(14.0)$ & \\
\hline$<40$ & & $22(6.6)$ \\
\hline $40-60$ & & $150(45.3)$ \\
\hline$>60$ & & $159(48.0)$ \\
\hline \multicolumn{3}{|l|}{ Gender } \\
\hline Male & & $157(47.4)$ \\
\hline Female & & $174(52.6)$ \\
\hline \multicolumn{3}{|l|}{ Ethnicity } \\
\hline Non-bumiputera & & $47(14.2)$ \\
\hline Bumiputera & & $284(85.8)$ \\
\hline \multicolumn{3}{|l|}{ Marital Status } \\
\hline Single/Divorcee & & $21(6.3)$ \\
\hline Married & & $310(93.7)$ \\
\hline \multicolumn{3}{|l|}{ Occupation } \\
\hline Unemployed & & $196(59.2)$ \\
\hline Employed & & $135(40.8)$ \\
\hline Household income (RM/month) & $1300.0(2200.0)$ & \\
\hline$\leq R M 3000$ & & $269(81.3)$ \\
\hline$>\mathrm{RM} 3000$ & & $62(18.7)$ \\
\hline \multicolumn{3}{|l|}{ Staying With } \\
\hline Family/Relative/Friend & & $322(97.3)$ \\
\hline Alone & & $9(2.7)$ \\
\hline \multirow{2}{*}{\multicolumn{3}{|c|}{ Co-Morbid }} \\
\hline & & \\
\hline Yes & & $318(96.1)$ \\
\hline No & & $13(3.9)$ \\
\hline \multicolumn{3}{|l|}{ T2DM Complication } \\
\hline Yes & & $77(23.3)$ \\
\hline No & & $254(76.7)$ \\
\hline HbA1C (\%) & $7.0(1.7)$ & \\
\hline \multicolumn{3}{|l|}{ Diabetes control } \\
\hline Good Control (HbA1C $\leq 7 \%)$ & & $186(56.2)$ \\
\hline Poor Control ( $\mathrm{HbA} 1 \mathrm{C}>7 \%)$ & & $145(43.8)$ \\
\hline \multicolumn{3}{|l|}{ Received insulin therapy } \\
\hline Yes & & $80(24.2)$ \\
\hline No & & $251(75.8)$ \\
\hline \multicolumn{3}{|l|}{ Having glucometer } \\
\hline Yes & & $91(27.5)$ \\
\hline No & & $240(72.5)$ \\
\hline
\end{tabular}

The median (IQR) for duration of diabetes was 5.0 (8.0) years. The median (IQR) for HbA1C was 7.0 (1.7) \% and more than a half (56.2\%) had good glycaemic control. Majority of them had comorbidities (96.1\%) but without diabetesrelated complications (76.7) (Table 1). About three-quarters of them $(\mathbf{7 5 . 8 \% )}$ were taking oral hypoglycaemic agents (OHA) only and $72.5 \%$ did not have a glucometer to monitor their blood sugar level at home. Among those who owned a glucometer, $35.2 \%$ were taking insulin.

Practice of diabetic self- care activities Taking diabetes medications was the most frequently practiced self-care activity by the participants (Table 2). The median (IQR) for taking diabetes medications was $7.0(0.0)$ days in a week. About $91 \%$ of them took the medications almost every day ( $\geq 6$ days in a week).

Following a healthful eating plan and inspecting feet were practiced moderately in an average of 4 to 5 days a week, whereas performing regular physical activity and monitoring blood glucose level were poorly practiced (Table 2). Among 91 participants who owned a glucometer, 35.2\% were taking insulin. Their median (IQR) days per week of monitoring blood glucose level was 1.0 (1.0) days. About $87 \%$ of these participants monitored their blood glucose level in two days per week or 
less. The second least practiced self-care activity was performing regular physical activity [median (IQR): 1.0 (4.0) days per week]. Majority of them (68.0\%) exercised for 30 minutes in two days per week or less and only $20.8 \%$ of them did so almost every day ( $\geq 6$ days in a week).
Prevalence of depression, anxiety and stress In this study, the proportion of those with depression, anxiety and stress were $4.5 \%, 8.8 \%$ and $5.7 \%$ respectively (Figure 2 ).

Table 2: Practice of self-care activities (days/week) among the participants ( $N=331$ )

\begin{tabular}{lcccc}
\hline \multicolumn{1}{c}{ Self-care activities (days per week) } & $\begin{array}{c}\text { Median } \\
(\text { IQR) }\end{array}$ & $\begin{array}{c}\mathbf{\leq} \text { days } \\
\mathbf{n}(\%)\end{array}$ & $\begin{array}{c}3-5 \text { days } \\
\mathbf{n}(\%)\end{array}$ & $\begin{array}{c}\geq 6 \text { days } \\
\mathbf{n}(\%)\end{array}$ \\
\hline Following a healthful eating plan & $5.0(4.0)$ & $62(18.7)$ & $145(43.8)$ & $124(37.5)$ \\
Performing regular physical activity & $1.0(4.0)$ & $225(68.0)$ & $37(11.2)$ & $69(20.8)$ \\
Inspecting feet & $4.0(7.0)$ & $143(43.2)$ & $30(9.1)$ & $158(47.7)$ \\
Monitoring blood glucose level & & & & \\
$\quad$ Among patients on OHA only & $0.0(1.0)$ & $242(96.4)$ & $6(2.4)$ & $3(1.2)$ \\
Among patients on insulin \pm OHA & $0.0(1.0)$ & $76(95.0)$ & $3(3.8)$ & $1(1.2)$ \\
$\quad$ Among patients who owned glucometer & $1.0(1.0)$ & $79(86.8)$ & $8(8.8)$ & $4(4.4)$ \\
Taking diabetes medications & $7.0(0.0)$ & $8(2.4)$ & $23(6.9)$ & $300(90.6)$ \\
\hline
\end{tabular}

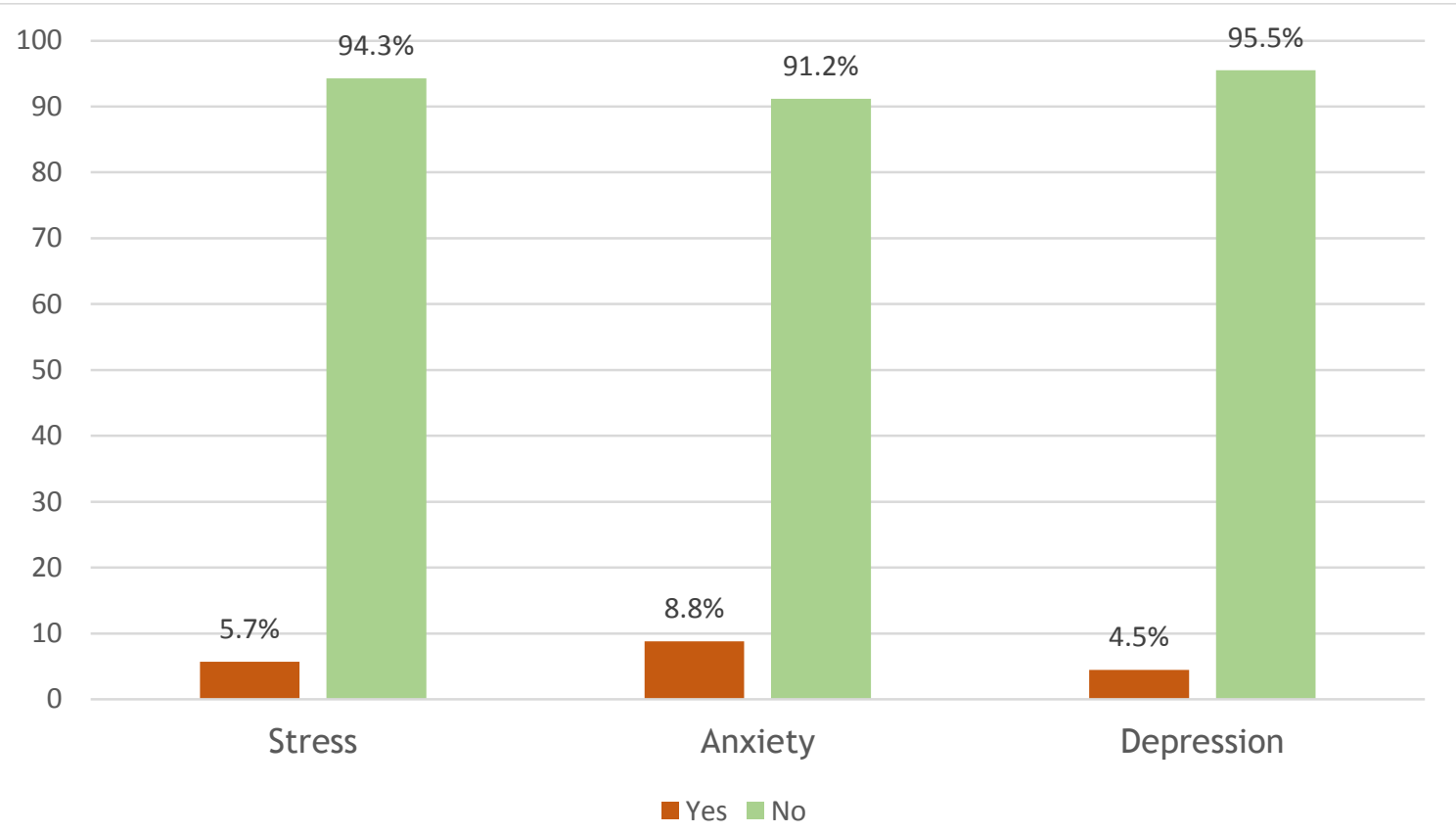

Figure 2: Prevalence of stress, anxiety and depression among the participants $(\mathrm{N}=331)$

The association between practice of the selfcare activities and psychological problems

Following a healthful eating plan $(p<0.001)$ was the only practice found to be significantly associated with anxiety (Table 3 ). Those with anxiety followed a healthful eating plan in fewer days per week than those without. The median (IQR) number of days per week for following a healthful eating plan among the participants with anxiety and without anxiety were $3.00(2.00)$ and 5.00 (4.00) days respectively. However, this selfcare activity was not significantly associated with depression $(p=0.120)$ and stress $(p=0.084)$. Practice of other self-care activities also did not show significant associations with any of the psychological problems as shown by Table 3 .
The association of self-care activities and psychological problems with HbA1c

Taking diabetes medications $(p=0.001)$ and following a healthful eating plan $(p<0.001)$ were found to be significantly associated with $\mathrm{HbA} 1 \mathrm{C}$ (Table 4). The more days they practiced these self-care activities, the lower their HbA1c; the correlations ( $r$ ) using Spearman's Rho for taking diabetes medications and following a healthful eating plan were -0.18 and -0.32 respectively. However, other self-care activities were not significantly correlated with HbA1c.

Table 5 shows that the HbA1c levels of those with depression, anxiety and stress were higher compared to the participants who had no psychological problems, but these differences were not statistically significant (HbA1C and depression: $p=0.838 ; \mathrm{HbA} 1 \mathrm{c}$ and anxiety: $\mathrm{p}=0.644$; HbA1c and stress: $p=0.168$ ). 
Table 3: Association of stress, anxiety and depression with practice of self-care activities $(\mathrm{N}=331)$

\begin{tabular}{|c|c|c|c|c|c|c|c|c|c|}
\hline \multirow[b]{2}{*}{$\begin{array}{l}\text { Self-care activities } \\
\text { (days per week) }\end{array}$} & \multicolumn{3}{|c|}{ Stress } & \multicolumn{3}{|c|}{ Anxiety } & \multicolumn{3}{|c|}{ Depression } \\
\hline & $\begin{array}{c}\text { Yes } \\
(n=19)\end{array}$ & $\begin{array}{c}\text { No } \\
(n=312)\end{array}$ & $\begin{array}{c}\mathrm{p}- \\
\text { value }\end{array}$ & $\begin{array}{c}\text { Yes } \\
(n=29)\end{array}$ & $\begin{array}{c}\text { No } \\
(n=302)\end{array}$ & $\begin{array}{c}\mathrm{p}- \\
\text { value }\end{array}$ & $\begin{array}{c}\text { Yes } \\
(n=15)\end{array}$ & $\begin{array}{c}\text { No } \\
(n=316)\end{array}$ & $\begin{array}{c}\mathrm{p}- \\
\text { value }\end{array}$ \\
\hline $\begin{array}{l}\text { Following a } \\
\text { healthful eating } \\
\text { plan [Median } \\
\text { (IQR)] }\end{array}$ & $\begin{array}{c}4.00 \\
(2.00)\end{array}$ & $\begin{array}{l}5.00 \\
(4.00)\end{array}$ & 0.084 & $\begin{array}{l}3.00 \\
(2.00)\end{array}$ & $\begin{array}{l}5.00 \\
(4.00)\end{array}$ & $<0.001$ & $\begin{array}{c}3.50 \\
(3.00)\end{array}$ & $\begin{array}{l}5.00 \\
(4.00)\end{array}$ & 0.120 \\
\hline $\begin{array}{l}\text { Performing } \\
\text { regular physical } \\
\text { activity [Median } \\
\text { (IQR)] }\end{array}$ & $\begin{array}{l}2.00 \\
(5.00)\end{array}$ & $\begin{array}{l}1.00 \\
(4.00)\end{array}$ & 0.324 & $\begin{array}{l}2.00 \\
(7.00)\end{array}$ & $\begin{array}{l}1.00 \\
(3.00)\end{array}$ & 0.304 & $\begin{array}{l}1.00 \\
(3.00)\end{array}$ & $\begin{array}{l}1.00 \\
(4.00)\end{array}$ & 0.922 \\
\hline $\begin{array}{l}\text { Inspecting foot } \\
\text { [Median (IQR)] }\end{array}$ & $\begin{array}{l}2.00 \\
(7.00)\end{array}$ & $\begin{array}{c}4.00 \\
(7.00)\end{array}$ & 0.655 & $\begin{array}{l}5.00 \\
(7.00)\end{array}$ & $\begin{array}{l}4.00 \\
(7.00)\end{array}$ & 0.878 & $\begin{array}{l}1.00 \\
(7.00)\end{array}$ & $\begin{array}{l}4.00 \\
(7.00)\end{array}$ & 0.347 \\
\hline $\begin{array}{l}\text { Monitoring blood } \\
\text { glucose level* } \\
\text { [Median (IQR)] }\end{array}$ & $\begin{array}{l}1.00 \\
(2.00)\end{array}$ & $\begin{array}{c}1.00 \\
(1.00)\end{array}$ & 0.333 & $\begin{array}{l}1.00 \\
(2.00)\end{array}$ & $\begin{array}{l}1.00 \\
(1.00)\end{array}$ & 0.757 & $\begin{array}{l}0.50 \\
(2.00)\end{array}$ & $\begin{array}{c}1.00 \\
(1.00)\end{array}$ & 0.703 \\
\hline $\begin{array}{l}\text { Taking diabetes } \\
\text { medications } \\
\text { [Median (IQR)] }\end{array}$ & $\begin{array}{l}7.00 \\
(0.00)\end{array}$ & $\begin{array}{l}7.00 \\
(0.00)\end{array}$ & 0.970 & $\begin{array}{l}7.00 \\
(0.00)\end{array}$ & $\begin{array}{l}7.00 \\
(0.00)\end{array}$ & 0.999 & $\begin{array}{l}7.00 \\
(0.00)\end{array}$ & $\begin{array}{l}7.00 \\
(0.00)\end{array}$ & 0.856 \\
\hline
\end{tabular}

*Only among patients who owned glucometer

Table 4: Association between self-care activities and HbA1c $(\mathrm{N}=331)$

\begin{tabular}{lcc}
\hline \multicolumn{1}{c}{ Self-care activities } & $\mathrm{r}$ & $\mathrm{p}$-value \\
\hline Following a healthful eating plan & -0.32 & $<0.001$ \\
Performing regular physical activity & -0.04 & 0.442 \\
Inspecting feet & 0.08 & 0.135 \\
Monitoring blood glucose level* & 0.12 & 0.267 \\
Taking diabetes medications & -0.18 & $\mathbf{0 . 0 0 1}$ \\
\hline
\end{tabular}

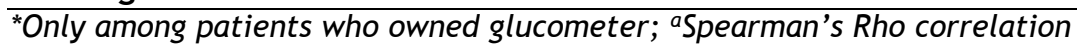

Table 5: Association of stress, anxiety and depression with HbA1c $(\mathrm{N}=331)$

\begin{tabular}{lccccccccc}
\hline & \multicolumn{3}{c}{ Stress } & \multicolumn{3}{c}{ Anxiety } & \multicolumn{3}{c}{ Depression } \\
\cline { 2 - 10 } & $\begin{array}{c}\text { Yes } \\
(\mathrm{n}=19)\end{array}$ & $\begin{array}{c}\text { No } \\
(\mathrm{n}=312)\end{array}$ & $\begin{array}{c}\mathrm{p}- \\
\text { value }\end{array}$ & $\begin{array}{c}\text { Yes } \\
(\mathrm{n}=29)\end{array}$ & $\begin{array}{c}\text { No } \\
(\mathrm{n}=302)\end{array}$ & $\begin{array}{c}\mathrm{p}- \\
\text { value }\end{array}$ & $\begin{array}{c}\text { Yes } \\
(\mathrm{n}=15)\end{array}$ & $\begin{array}{c}\text { No } \\
(\mathrm{n}=316)\end{array}$ & $\begin{array}{c}\mathrm{p}- \\
\text { value }\end{array}$ \\
\hline HbA1c [Median & 8.1 & 6.9 & 0.168 & 7.3 & 6.9 & 0.644 & 7.0 & 7.0 & 0.838 \\
$($ IQR)] & $(3.4)$ & $(1.6)$ & & $(2.5)$ & $(1.6)$ & & $(2.7)$ & $(1.7)$ & 0.838 \\
\hline
\end{tabular}

\section{DISCUSSION}

The majority of the participants in this study were Bumiputera (i.e. natives of Sabah) who were married and living with others, thus, it indicates that they might have good family support system. The average monthly income of the participants (RM 1300) was far below the median income of Sabah (RM 4110 per month) and at least four-fifths of them belonged to the bottom $40 \%$ of the Malaysian population (B40 group). ${ }^{37}$ These findings show that most of them were from low income families. There is also a possibility that a majority of them were not a long-standing diabetic patient as the average duration of their illness was only five years. This finding is in line with other common characteristics of the participants whereby most of them did not have any diabetic complications and more than a half had good diabetes control.

In this study, the various self-care activities were practiced at varying degree. Taking diabetes medications was the most frequently practiced self-care activity by the participants. This finding represents their good adherence to diabetic medications which is similar to other studies worldwide. ${ }^{11-15}$ The high level of practice in taking medications among the participants may be because they perceived that the medications are more important than the other self-care activities. $^{20}$

The least practiced self-care activities was monitoring blood glucose level, similarly observed in less developed countries such as Saudi Arabia, Iran, Taiwan and Turkey. ${ }^{11-13,15}$ In fact, the level of monitoring blood glucose by our participants was noted to be even lower than these countries ${ }^{11-13,15}$ and those in peninsular Malaysia. ${ }^{16,17,19}$ Financial constraint faced by majority of the participants who came from low income families may be the cause of this practice as only $27.5 \%$ of the participants owned a glucometer. Since the test strips are expensive, these participants could not afford to practice this self-care activity more 
frequently. Moreover, this practice may be deemed unnecessary because the majority did not use insulin. ${ }^{4}$ Less frequent glucose monitoring also appears to be more appropriate for more than a half of the participants as their diabetes control was generally good.

The second least practiced self-care activity in this study was exercising for 30 minutes a day, which was lesser than those practiced by diabetic patients in peninsular Malaysia. ${ }^{16-19}$ Since majority of Sabahan were considered physically active by a national study ${ }^{2}$, the contradictory findings may suggest that the participants did not participate in specific exercise sessions but remained active through daily activities. This postulation is supported by Poh et al. (2010) which found only 18.6\% Sabahan performed regular exercise for at least 20 minutes in 3 times a week. ${ }^{38}$

Generally, the psychological problems among patients with T2DM in this study were uncommon compared to other studies done in Malaysia. $22-25$ These findings were unexpected since Sabah had the highest prevalence of mental health problems in Malaysia and convenience sampling might be the cause of it. $^{2}$ Furthermore, those with psychological problems might refuse to participate as the questionnaire was long and time-consuming to complete.

In this study, good adherence to a healthful eating plan by our participants was significantly correlated with lower $\mathrm{HbA1c}$ level, indicating the importance of this practice to ensure good diabetic control. Since those with anxiety were less compliant to a healthful eating plan compared to those without, there is a possibility that they might feel worried when they derailed from the expected eating behaviour. ${ }^{31}$ This postulation is in line with the finding that showed a higher HbA1c level among those with anxiety compared to those without. They might realise that maintaining good diabetic control is difficult for them. However, this difference was insignificant due to type II error as a result of small sample size.

This study did not show any significant association between other self-care activities and any of the psychological problems. These findings are contradictory to previous studies particularly the ones that showed significant associations of selfcare activities with depression. ${ }^{26-33}$ The nonsignificant findings in our study may be because depression and stress were not prevalent among the participants. Less than 20 participants out of 331 suffered from depression or stress and this small sample size may influence the significance of the bivariate analysis.

The strength of this study was the use of adequate sample size to represent the level of self-care activities of the patients with T2DM from the public health clinic. However, the convenience sampling used in this study may limit the generalisability of the findings. This method of sampling was used due to limitation of the data collection period and high refusal rate among those who met the study criteria. They became discouraged to complete the questionnaire as it was long and time-consuming to complete. Nevertheless, this study can be considered as a pilot study that assessed self-care activities practiced by diabetes patients in Sabah, their psychological problems and the associations between the two. The findings of this study could still provide a basic knowledge for future studies involving this population. A case control study design and the use of simplified questionnaire are recommended.

\section{CONCLUSION}

Generally, the self-care activities were practiced in varying degree by the patients with T2DM in this study. Taking diabetic medications was the most frequently practiced self-care activity which indicates their good adherence to medications. Monitoring blood sugar levels and performing regular exercise were the least performed. Following a healthful eating plan was found to be significantly associated with anxiety but not depression and stress. Other practice of self-care activities also did not show significant associations with any of the psychological problems. Therefore, healthcare providers should encourage and empower them to perform selfcare activities. Even though psychological problems appear to be uncommon, presence of anxiety should not be ignored as it could impair adherence to a healthful eating plan. Its presence should be screened and managed in a hope to improve their compliance and diabetic control.

\section{ACKNOWLEDGEMENTS}

The authors would like to thank the Director General of Health Malaysia for permission to publish this paper. This study was not funded by any organization. Special thanks to the Family Medicine Specialist of the health clinic and all clinic staff who had given their support and assistance. This study was supported by the Universiti Kebangsaan Malaysia (FF-2016-116).

\section{REFERENCES}

1. World Health Organization. Global Report on Diabetes. Geneva: World Health Organization 2016. http://apps.who.int/iris/bitstream/1066 5/204871/1/9789241565257_eng.pdf (accessed 22 January 2019).

2. Institute for Public Health (IPH). National Health and Morbidity Survey 2015 (NHMS 2015) Vol. II: Non-Communicable Diseases, Risk Factors \& Other Health Problems; 2015. 
3. Institute for Public Health (IPH). National Health and Morbidity Survey 2011: Fact Sheet; 2011.

4. American Diabetes Association (ADA). Standards of Medical Care in Diabetes 2017: Abridged for Primary Care Providers. Diabetes Care 2017; 40(1): S1S135.

5. Toobert D, Hampson S, Glasgow R. The summary of Diabetes Self-care Activities Measure. Result from 7 studies and a revised scale. Diabetes Care 2000; 23(7); 943-50.

6. Song M, Ratcliffe SJ, Tkacs NC, et al. Selfcare and health outcomes of diabetes mellitus. Clin Nurs Res 2012; 21(3): 30926.

7. Jannoo Z, Wah YB, Lazim AM, et al. Examining diabetes distress, medication adherence, diabetes self- care activities, diabetes-specific quality of life and health-related quality of life among type 2 diabates mellitus patients. J Clin Transl Endocrinol 2017; 9: 48-54.

8. Hou YY, Li W, Qiu JB, et al. Efficacy of blood glucose self-monitoring on glycaemic control in patient with noninsulin-treated type2 diabetes: A metaanalysis. Int J Nurs Sci 2014; 1(2): 191-5.

9. Coyle ME, Francis K, Chapman Y. Selfmanagement activities in diabetes care: $\mathrm{A}$ systematic review. Aust Health Rev 2013; 37: 513-22.

10. Shigaki C, Kruse RL, Mehr D, et al. Motivation and diabetes selfmanagement. Chronic Illn 2010; 6(3): 202-14.

11. Al Johani KA, Kendall GE, Snider PD. Selfmanagement practices among type 2 diabetes patients attending primary health-care centres in Medina, Saudi Arabia. East Mediterr Health J 2015; 21(9):621-8.

12. Tol A, Shojaeezadeh D, Eslami A, et al. Evaluation of self-care practices and relative components among type 2 diabetic patients. J Educ Health Promot 2012; $1: 19$

13. Wu SFV, Huang YC, Liang SY, et al. Relationships among depression, anxiety, self-care behavior and diabetes education difficulties in patients with type-2 diabetes: A cross-sectional questionnaire survey. Int J Nurs Stud 2011; 48(11):137683.
14. Simon-Tuval T, Smueli A, Harman-Boehm I. Adherence to self- care behaviours among Type 2 Diabetes - The role of risk preference. Value Health 2016; 19(6): 844-51.

15. Kav S, Yilmaz AA, Bulut $Y$, et al. Selfefficacy, depression and self-care activities of people with type 2 diabetes in Turkey. Collegian 2017; 24(1): 27-35.

16. Siti Khuzaimah AS, Aini A, Surindar Kaur SS, et al. Self-care behaviour among type 2 diabetes patients. Pertanika J Sci \& Technol 2014; 22(2): 471-88.

17. Bariyyah NKMH, Bujang MA, Baharum N, et al. Self-care activities among diabetic patients and factors affecting glycaemic control in primary health care, Malaysia. J Diabetes Clin Prac 2018; 1: 103.

18. Tharek Z, Ramli AS, Whitford DL, et al. Relationship between self-efficacy, selfcare behaviour and glycaemic control among patients with type 2 diabetes mellitus in the Malaysian primary care setting. BMC Family Practice 2018; 19: 39.

19. Yee KC, Md Said S, Abdul Manaf R, et al. Identifying self-care behaviour and its predictors among type 2 diabetes mellitus patients at a district of Northern Peninsular Malaysia. Mal J Med Health Sci 2018; 14(2): 17-29.

20. Luo X, Liu T, Yuan X, et al. Factors influencing self-management in Chinese adults with type 2 diabetes: A systematic review and meta-analysis. Int $J$ Environ Res Public Health 2015; 12(9): 11304-27.

21. Wilkinson A, Whitehead L, Ritchie L. Factors influencing the ability to selfmanage diabetes for adults living with type 1 or 2 diabetes. Int J Nurs Stud 2014; 51(1): 111-22.

22. Ganasegaran K, Renganathan P, Abdul Manaf $\mathrm{R}$, et al. Factors associated with anxiety and depression among type 2 diabetes outpatients in Malaysia: A descriptive cross-sectional single-centre study. BMJ Open 2014; 4: e004794.

23. Kaur G, Tee GH, Ariaratnam S, et al. Depression, anxiety and stress symptoms among diabetic in Malaysia: A cross sectional study in an urban primary care setting. BMC Family Practice 2013; 14: 69.

24. Mohamed R, Abdul Kadir A, Yaacob LH. A study on depression among patient with 
type 2 diabetes mellitus in north-east coast Malaysia. International Journal of Collaborative Research on Internal Medicine \& Public Health 2012; 4(8): 1589-600.

25. Abd. Hamid S, Ab. Manan N. Stress coping skills among diabetes sufferers in Sepang Selangor Malaysia. International Journal of Education and Research 2013; 1(10): 1 10.

26. Sumalin LL, Garcia TJ, Brown SA. Depression and adherence to lifestyle changes in type 2 diabetes: A systematic review. Diabetes Educ 2014; 40(6): 731 44.

27. Gonzalez JS, Peyrot M, MCCarl LA, et al. Depression and diabetes treatment nonadherence: A Meta-Analysis. Diabetes Care 2008; 31:2394-403.

28. Gonzalez JS, Safren SA, Cagliero E, et al. Depression, self-care, and medication adherence in type 2 diabetes: Relationships across the full range of symptom severity. Diabetes Care 2007; 30(9): 2222-7.

29. Lin EHB, Katon W, Von Korff $M$, et al. Relationship of depression and diabetes self-care, medication adherence, and preventive care. Diabetes Care 2004; 27:2154-60.

30. Walker RJ, Gebregziabher M, MartinHarris B, et al. Independent effects of socioeconomic and psychological social determinants of health on self-care and outcomes in type 2 diabetes. Gen Hosp Psychiatry 2014; 36(6): 662-8.

31. Maneze D, Everett B, Astorga C, et al. The influence of health literacy and depression on diabetes self-management: A cross-sectional study. J Diabetes Res 2016; 2016: 3458969.

32. Egede LE, Ellis C, Grubaugh AL. The effect of depression on self- care behaviours and quality of care in a national sample of adults with diabetes. Gen Hosp Psychiatry 2009; 31 (5): 422-7.

33. Al-Hayek AA, Robert AA, Alzaid AA, et al. Association between diabetes self-care, medication adherence, anxiety, depression, and glycemic control in type 2 diabetes. Saudi Med J 2012; 33(6):6813.

34. Jalaludin MY, Fuziah MZ, Hong JYH, et al. Reliability and Validity of the Revised Summary of Diabetes Self-Care Activities
(SDSCA) for Malaysian Children and Adolescent. Malays Fam Physician 2012; 7(2-3): 10-20.

35. Bujang MA, Ismail M, Bariyyah NK, et al. Validation of the summary of diabetes self-care activities (SDSCA) in Malay language for Malaysian adults. MJPHM 2016; 16(3): 227-34.

36. Musa R, Fadzil MA, Zain Z. Translation, validation and psychometric properties of Bahasa Malaysia version of the Depression, Anxiety and Stress Scales (DASS). ASEAN Journal of Psychiatry 2007; $8(2): 82-9$.

37. Department of Statistics Malaysia. Report of household income and basic amenities survey

2016.https: / /www.dosm.gov.my/v1/inde $\mathrm{x} . \mathrm{php}$ ? $\mathrm{r}=$ column $/$ cthemeByCat\&cat=120\& bul_id=RUZ5REwveU1ra1hGL21JWVIPRmU 2Zz09\&menu_id=amVoWU54UTI0a21NWm dhMjFMMWcyZz09 (accessed 22 January 2019).

38. Poh BK, Safiah MY, Tahir A, et al. Physical activity pattern and energy expenditure of Malaysian adults: Findings from the Malaysian Adult Nutrition Survey (MANS). Mal J Nutr 2010; 16(1): 13-37. 